DAVID FERNÁNDEZ-QUIJADA MARINA RAMOS-SERRANO (eds.)

TECNOLOGIAS DE LA PERSUASIÓN USO DE LAS TIC EN PUBLICIDAD Y RELACIONES PÚBLICAS

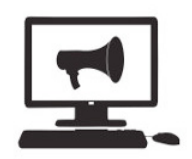

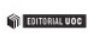

Tecnologías de la persuasión. Uso de las TIC en publicidad y relaciones públicas

David Fernández-Quijada y Marina Ramos-Serrano

(Editores)

Editorial UOC

\title{
Tecnologías de la persuasión. Uso de las TIC en publicidad y relaciones públicas
}

$\mathrm{D}$ iversos profesores e investigadores de la Facultad de Comunicación de la Universidad de Sevilla, entre los que figuran Antonio Pineda Cachero, Víctor Hernández Santaolalla y Gloria Jiménez Marín han colaborado en este manual como expertos en propaganda o comunicación comercial, coeditado por David Fernández-Quijada y Marina Ramos- Serrano.

La obra consta de un conjunto de interesantes artículos que giran en torno al uso de las TIC en Publicidad y Relaciones Públicas. En un primer momento se hace referencia a las relaciones "de conveniencia" entre comunicación comercial y tecnologías, refiriendo numerosos ejemplos de esta dualidad.

Con una estructura conformada por diez capítulos más uno con carácter introductorio, se pretende el estudio de la tecnología desde la comunicación comercial. En esta introducción se revisan diversos conceptos relacionados con la tecnología y se establecen las principales consecuencias de la aplicación de la misma en publicidad y relaciones públicas, estableciendo el punto de arranque para las investigaciones expuestas a lo largo de los diez capítulos sucesivos. 
Cada uno de los diez capítulos se encuentran estructurados de manera que, tras cada uno de los desarrollos temáticos, se encuentran expuestas unas conclusiones $\mathrm{y}$, posteriormente la bibliografía (con recomendaciones de bibliografía complementaria), para finalizar con unas preguntas que incitan a la reflexión y al debate en torno a la temática desarrollada en cada una de las aportaciones y que ponen de manifiesto el carácter didáctico de la obra.

Tomando como punto de partida la incidencia social de las TIC, se presentan una selección de casos relacionados con el ámbito de las TIC en la publicidad a través de diferentes soportes digitales, desde el corporativismo en internet, pasando por las comunidades de marca en Facebook, blogs y moda, comunicación viral, Instagram o el empleo del podcasting en el ámbito de las relaciones públicas. En definitiva, la obra abarca el empleo práctico de diversos instrumentos, herramientas y experiencias englobadas en el mundo digital, mostrándonos el impacto de cada uno de ellos en la comunicación sociocéntrica. Junto a ello se refieren estrategias dirigidas a la persuasión del público, en definitiva, al consumidor o incluso prosumidor mediático, mostrándonos las últimas tendencias en este ámbito: el appvertising, que vendría definido como el conjunto de acciones publicitarias desarrolladas a través del uso de aplicaciones móviles, que vinculan una experiencia de entretenimiento a una marca, producto o servicio.

Resulta indudable el poder que las tecnologías ofrecen en el ámbito de la publicidad y las relaciones públicas. Una ingente cantidad de recursos, aplicaciones y herramientas que van a contribuir al enriquecimiento de la persuasión en este apasionante campo del conocimiento.

$\mathrm{M}^{\mathrm{a}}$ Montserrat Vaqueiro Romero

Grupo de investigación GRILES (Universidad de Vigo) Profesora tutora UNED (Grados de Lengua Española, Estudios Ingleses e $H^{a}$ del Arte) Coordinadora CUID- Lengua Gallega 